\title{
Perianal Extramammary Paget's Disease: Diagnosis, Treatment and Prognosis
}

Francesca De Felice ${ }^{1^{*}}$, Daniela Musio ${ }^{1}$, Rossella Caiazzo ${ }^{1}$, Alessandra Pieroni ${ }^{1}$, Michele Carnevale ${ }^{1}$, Francesca Salerno ${ }^{1}$ and Vincenzo Tombolini ${ }^{1,2}$

${ }^{1}$ Department of Oncological and Radiological Sciences Anatomy and Pathological , Catterdra of Radiotherapy, University of Rome " Sapienza" Viale Regina Elena 155, 00161 Rome, Italy

${ }^{2}$ Spencer-Lorillard Foundation, Viale Regina Elena 262,00161 Rome, Italy

*Corresponding author: Francesca De Felice, Department of Oncological and Radiological Sciences Anatomy and Pathological , Catterdra of Radiotherapy, University of Rome " Sapienza" Viale Regina Elena 155, 00161 Roma, Italy, Tel: 06-49973404 ; Fax: 0649973411 ; E-mail: fradefelice@hotmail.it

Rec Date: Jul 23, 2014, Acc Date: Sep 09, 2014, Pub Date: Sep 11, 2014

Copyright: ( 2014 Felice FD, et al. This is an open-access article distributed under the terms of the Creative Commons Attribution License, which permits unrestricted use, distribution, and reproduction in any medium, provided the original author and source are credited.

\begin{abstract}
Background: To make an update on the state of knowledge on perianal extramammary Paget's disease.

Case presentation: We report one case as an illustration of this rare, slow-growing and occasionally metastasizing entity.

The standard treatment is a local surgical excision. Radiation therapy is recommended as primary treatment in inoperable patients, and as alternative to surgery for recurrence disease previously excised or in case of mutilating surgery.

Conclusions: Definitive conclusion cannot be drawn. Clinical trials are required to test whether radiation therapy is advantageous as primary treatment approach, compared to surgery.
\end{abstract}

Keywords : Extramammary; Paget's disease; Perianal; Treatment; Diagnosis; Prognosis

\section{Introduction}

Extramammary Paget's disease (EMPD) is a rare, slow-growing and occasionally metastasizing neoplasm. Its pathophysiology is still poorly understood. It is associated with synchronous or metachronous malignancies in $50 \%$ of cases [1]. EMPD most frequently affected vulva, penis and scrotum areas, but perianal involvement has also been described, although the incidence of this localization is less than $6.5 \%$ of all cases of EMPD and less than 200 cases have been reported in literature [2].

The aim of this study is to report a case of perianal EMPD and to illustrate the diagnostic, therapeutic and prognostic aspects of this entity, of which, despite its rarity, dermatologist and clinicians treating gastrointestinal and gynaecological tumours should be aware.

\section{Case Presentation}

A 71-year-old Caucasian female, without previous medical history, was referred to our Department for treatment and diagnostic work up for recurrent perianal EMPD.

History disease dated back March 2011, when, due to skin change followed by progressive pruritus, patient sought medical attention. Biopsy of perianal lesion was performed and it revealed an EMPD. Staging computed tomography (CT) of chest, abdomen, and pelvis were negative, such as cystoscopy, colonoscopy and hysteroscopy. In May 2011, patient was submitted to a local excision of the perianal lesion and to a reconstruction of the defect with skin graft taken from her thigh. Pathology confirmed biopsy diagnosis. The cut surface of the perianal skin demonstrated the lesion to be white, with a greatest depth of $0.5 \mathrm{~cm}$ and microinvasion into the stroma. Tumour cells had abundant clear cytoplasm with round vesicular nuclei. They spread into the epidermis in small nest patterns and formation of numerous small duct-like structures was evident. The Paget cells were EMA positive, Her-2 positive and S-100 negative. There was no evidence of lymphovascular invasion.

Nineteen months later, EMPD was found to be progressing again in the same area. A repeat biopsy revealed an extramammary Pageat aspect. Follow-up CT imaging confirmed pathological perianal tissue, with adipose tissue disomogeneity. Bilateral inguinal lymph nodes were documented. Initial treatment was topical therapy. Because of disease local progression, patient was referred to our Department. Patient underwent an extensive diagnostic evaluation to rule out the possibility of an occult carcinoma. Dermatological abnormalities that had appeared were noted: a rash on perianal and vulvar areas, with erythematous plaque, inflammatory and erosive lesions (Figure 1a). Patient was treated in June 2013 with an exclusive course of radiation therapy: $45 \mathrm{~Gy}$ in 25 fractions ( $1.8 \mathrm{cGy} / \mathrm{fr}$ ) over 5 weeks, to the pelvis lymph nodes external and internal iliac, obturator, presacral and inguinal -, plus $14.4 \mathrm{~Gy}(1.8 \mathrm{cGy} / \mathrm{fr})$ to the tumour volume, using 6 MV energy photons. Patient lied in the prone position; a belly-board device was used to displace the small bowels out of the treatment field; a radio-opaque solution was placed around the perianal area to better define the tumour extension on the planning CT scan. Treatment was well tolerated, with no interruptions. At November 2013, the patient is still alive, with no evidence of disease (Figure 1b).

\section{Discussion}

EMPD is an uncommon entity. Since its first description in 1874 [3] of what is nowadays known as Paget's disease of the nipple, analogous lesions have been described in anogenital region, lower urinary tract, 
axilla, oral cavity and eyelids [4]. Darier and Coulillaud [5], in 1893 described the first patient with EMPD involving the perianal area. Perianal EMPD accounts for less than $1 \%$ of anal disease and affects more commonly female, with a peak of incidence of 60 year old [6]. Several difficulties are combined to make a clinical diagnosis of this condition [7]. It is characterized by leukoplakia-like and/or ulceration area, hyperpigmentation and superimposed infection. Pruritus is the most common presenting symptom. Because of its non-specific features, perianal EMPD could be misdiagnosis as an infective or inflammatory skin status, such as eczema or contact dermatitis [8].

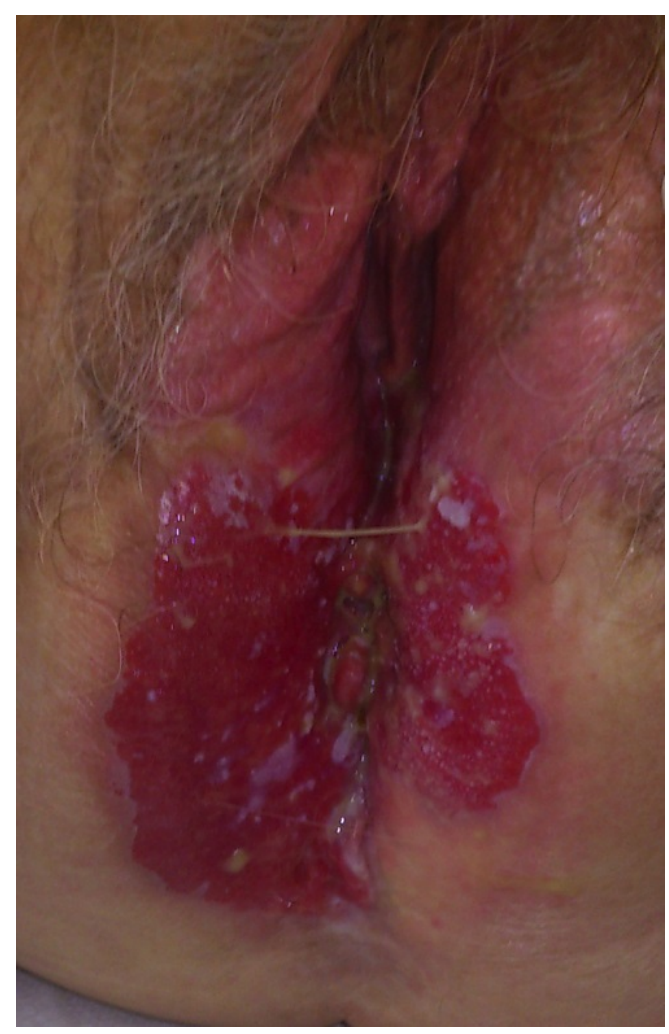

Figure 1a: Pre treatment evaluation

Perianal EMPD is often associated with anal or colon-rectum carcinoma. Therefore an accurate diagnostic evaluation of gastrointestinal tract is mandatory, and a more extensive evaluation should be done to rule out occult primary carcinomas [9].

Due to its rarity, little is known about its prognostic factors and optimal treatment. Published data in the medical literature consist of retrospective studies or small case series, only.

The prognosis for perianal EMPD confined to the epidermis is excellent; whereas dermal or lymph node invasion are associated with worse prognosis. But, at present, data are insufficient to confirm it solidly. Cases of EMPD with microscopic $(<1 \mathrm{~mm})$ dermal invasion are proposed to have a more favourable prognosis than lesions showing deeper invasion or lymphovascular invasion [8].

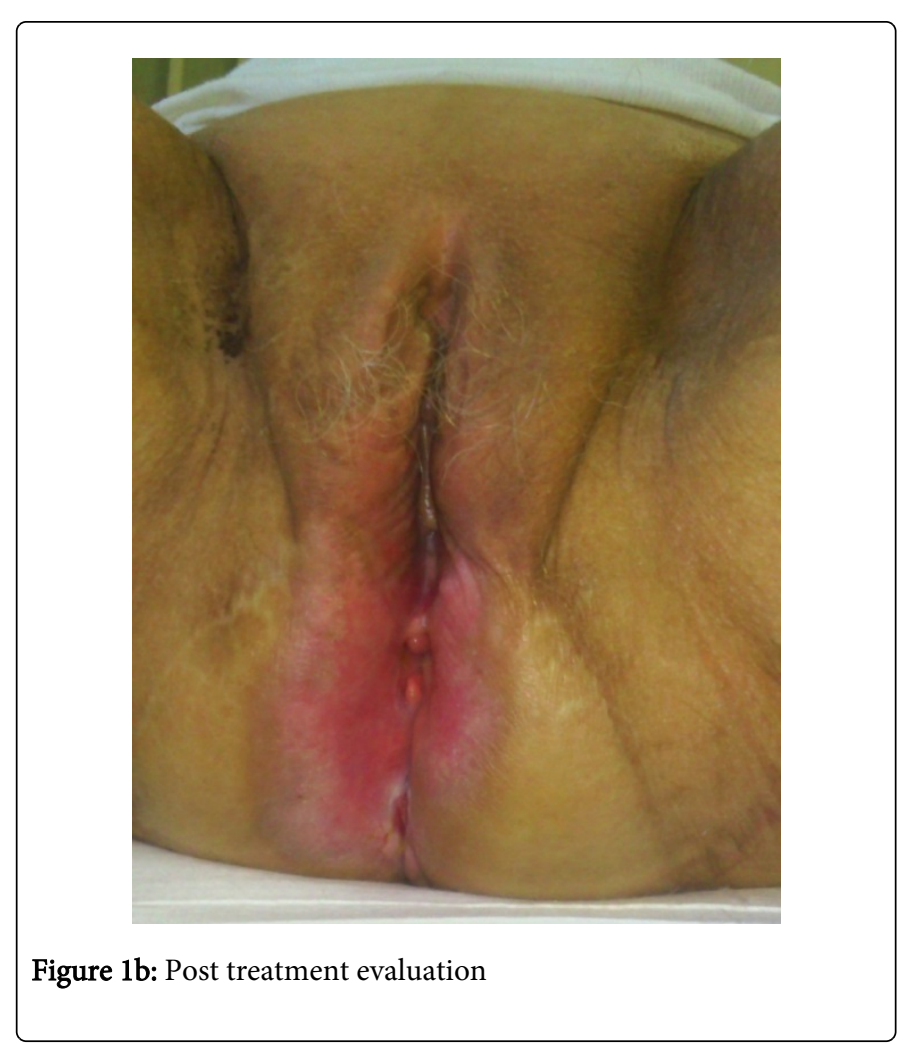

The standard treatment is a local surgical excision, with at least 1 $\mathrm{cm}$ to $1.5 \mathrm{~cm}$ margins of grossly visible tumour, with re-resection according to frozen section results, as recommended by the M.D. Anderson group [10]. The role of radiotherapy is not well defined in literature. Besa et al. [11] evaluated the influence of radiotherapy in a series of 65 patients with EMPD arising in the vulva, perianal area or scrotum. They recommended radiation therapy as primary treatment in inoperable patients, and as alternative to surgery for recurrence disease previously excised or in case of mutilating surgery. Al Hallak et al. [12] considered radiation therapy as an appropriate alternative approach in those patients unfit for surgery or who refuse surgical management to preserve functional integrity. Brown et al [13] described two possible uses of radiotherapy, as primary treatment or following surgical relapse. We presented a case of invasive perianal EMPD recurrence treated by definitively radiotherapy. Adequate information on radiation technique, field size and margins, doses, fractionation schedules and beam energy are poorly documented and the little technical details available are heterogeneous (Table 1). We chose to include the lymph nodes of the pelvis in the target volume, due to inguinal lymph nodes CT-documented. Based on anatomic knowledge - lymphatic drainage from perianal area is to the inguinal and femoral lymph nodes, and thence to the external iliac nodes - we considered pelvis at risk of microscopic disease. It is certain that lower doses of radiation therapy are associated with a higher risk of recurrences, therefore a radiation total dose greater than $50 \mathrm{~Gy}$ is necessary to improve local control $[2,11,13]$. There are no randomized controlled trials to compare surgery with radiotherapy for EMPD. Reports of definitive radiation therapy as primary approach are beginning to emerge in literature $[14,15]$, supporting the option that radiotherapy is a reasonable and viable primary treatment option in the management of these patients. 
Citation: De Felice F, Musio D, Caiazzo R, Pieroni A, Carnevale M, et al. (2014) Perianal Extramammary Paget's Disease: Diagnosis, Treatment and Prognosis. J Cytol Histol 5: 277. doi:10.4172/2157-7099.1000277

Page 3 of 3

\begin{tabular}{|l|l|l|l|l|}
\hline Author & $\begin{array}{l}\text { Total } \\
\text { dose }\end{array}$ & $\begin{array}{l}\text { Single } \\
\text { fraction }\end{array}$ & Field size & $\begin{array}{l}\text { Beam } \\
\text { energy }\end{array}$ \\
\hline $\begin{array}{l}\text { Mann et al. } \\
{[14]}\end{array}$ & $64 \mathrm{~Gy}$ & $2 \mathrm{~Gy}$ & $\begin{array}{l}\text { Vulvovaginal, and } \\
\text { perineum } \\
\text { perianal regions }\end{array}$ & - \\
\hline $\begin{array}{l}\text { Velenik et al. } \\
{[15]}\end{array}$ & $45 \mathrm{~Gy}$ & $3 \mathrm{~Gy}$ & GTV $+1.5 \mathrm{~cm}$ & $80 \mathrm{kV}$ \\
\hline $\begin{array}{l}\text { Bradley et al. } \\
{[16]}\end{array}$ & $40-50 \mathrm{~Gy}$ & - & $\mathrm{GTV}+3 \mathrm{~cm}$ & - \\
\hline $\begin{array}{l}\text { Thirlby et al. } \\
{[17]}\end{array}$ & $50 \mathrm{~Gy}$ & $2 \mathrm{~Gy}$ & - & $20 \mathrm{MeV}$ \\
\hline $\begin{array}{l}\text { Besa et al. } \\
{[11]}\end{array}$ & $56-64 \mathrm{~Gy}$ & $2 \mathrm{~Gy}$ & $12 \times 10$ & - \\
\hline Amin [6] & $50 \mathrm{~Gy}$ & $5 \mathrm{~Gy}$ & $15 \times 15$ area & $300 \mathrm{kV}$ \\
\hline
\end{tabular}

Table 1 : Radiation therapy technical details

\section{Conclusion}

Perianal EMPD is a rare but specific entity. The diagnosis is based on clinical and histopathological findings and extensive workup to rule out an underlying primary carcinoma is crucial. Surgical excision is the gold standard. Radiation therapy is an effective efficient alternative to surgery. But definitive conclusion can not be drawn. Clinical trials are required to test whether radiation therapy is advantageous as primary treatment approach, compared to surgery.

\section{References}

1. Balducci L, Crawford ED, Smith GF, Lambuth B, McGehee R, et al. (1988) Extramammary Paget's disease: an annotated review. Cancer Invest 6: 293-303.

2. Minicozzi A, Borzellino G, Momo R, Steccanella F, Pitoni F, et al. (2010) Perianal Paget's disease: presentation of six cases and literature review. Int J Colorectal Dis 25: 1-7.

3. Paget J (1874) On disease of the mammary areola preceding cancer of the mammary gland. Saint Bartholomew's Hospital Report 1087.

4. Perez MA, LaRossa DD, Tomaszewski JE (1989) Paget's disease primarily involving the scrotum. Cancer 63: 970-975.

5. Darier J, Coulillaud P (1893) Sur un cas de maladie de Paget de la région périnéo-anale et scrotale. Ann Dermatol Syphiligr 4: 25-31.

6. Amin R (1999) Perianal Paget's disease. Br J Radiol 72: 610-612.

7. Jabir S, Khatib M, Ali S, Niranjan N (2013) Perianal Paget's disease: a diagnostic dilemma. BMJ Case Rep 2013.

8. Lloyd J, Flanagan AM (2000) Mammary and extramammary Paget's disease. J Clin Pathol 53: 742-749.

9. Gaertner WB, Hagerman GF, Goldberg SM, Finne CO 3rd (2008) Perianal Paget's disease treated with wide excision and gluteal skin flap reconstruction: report of a case and review of the literature. Dis Colon Rectum 51: 1842-1845.

10. Hegarty PK, Suh J, Fisher MB, Taylor J, Nguyen TH, et al. (2011) Penoscrotal extramammary Paget's disease: the University of Texas M. D. Anderson Cancer Center contemporary experience. J Urol 186: 97-102.

11. Besa P, Rich TA, Delclos L, Edwards CL, Ota DM, et al. (1992) Extramammary Paget's disease of the perineal skin: role of radiotherapy. Int J Radiat Oncol Biol Phys 24: 73-78.

12. Al Hallak MN, Zouain N (2009) Extramammary Perianal Paget's Disease. Case Rep Gastroenterol 3: 332-337.

13. Brown RS, Lankester KJ, McCormack M, Power DA, Spittle MF (2002) Radiotherapy for perianal Paget's disease. Clin Oncol (R Coll Radiol) 14: 272-284.

14. Mann J, Lavaf A, Tejwani A, Ross P, Ashamalla H (2012) Perianal Paget disease treated definitively with radiotherapy. Curr Oncol 19: e496-500.

15. Velenik V, Segedin B, Anderluh F, Oblak I, Strojan P (2008) Radiotherapy for perianal Paget's disease: a case report. Tumori 94: 750-753.

16. Merritt BG, David G (2012) Brodland Extramammary Paget Disease. Springer edition, pp 263-278.

17. Thirlby RC, Hammer CJ Jr, Galagan KA, Travaglini JJ, Picozzi VJ Jr (1990) Perianal Paget's disease: successful treatment with combined chemoradiotherapy. Report of a case. Dis Colon Rectum 33: 150-152. 